\title{
Taste sensitivity in infrahuman species: Use of a genetic model to test the validity of alternative measures
}

T. W. KLEIN and J. C. DeFRIES, INSTITUTE FOR BEHAVIORAL GENETICS, UNIVERSITY OF COLORADO, Boulder, Colorado 80302

In a genetic analysis of PTC taste sensitivity of mice, Ss were presented tap water and a PTC solution in a two-choice situation. A preference index was used as a measure of taste sensitivity, assuming that ability to taste would lead to avoidance, i.e., negative preference. This assumption, however, lead to the rejection of seven Ss who preferred the test solution. Due to the undesirability of deleting Ss, the data were reanalyzed, using an alternative index of taste sensitivity that required no assumption concerning the hedonic quality of the test solution. Information regarding the inheritance of taste sensitivity to PTC provided the validating criterion for this measure.

The most widely used method for measuring taste sensitivity of human Ss has been that of Harris and Kalmus (1949). Derived from Fisher's classic tea-tasting experiment, this procedure consists of presenting the $S$ with a number of tumblers (usually eight), half of which contain water and the other half one of a number of serial dilutions of a test solution. The S's task is to sort the tumblers by taste. If the tumblers are initially sorted correctly, the concentration of the test solution is decreased until this can no longer be accomplished. If the initial sort is incorrect, concentration of the test solution is increased. The lowest concentration at which a successful sort is possible is taken as the S's threshold concentration.

The two-choice method provides an efficient analogous test procedure for research with infrahuman species that circumvents the necessity of teaching the $S$ a discrimination task prior to testing. With the two-choice method, the $S$ is presented two graduated cylinders with drinking tips, one of which contains water and the other a concentration of the test solution. The amount of liquid ingested from each cylinder is recorded periodically and the preference for the two solutions is ascertained, usually in terms of a preference ratio that is calculated by dividing the amount of the test solution consumed by the total amount of liquid ingested. The application of this method to the assessment of taste sensitivity requires the assumption that the ability to discriminate between two liquids will produce differential preference for them. Thus, a departure in the preference ratio from 0.5 in the two-choice situation is indicative of the $S$ 's ability to taste; however, a preference ratio of 0.5 does not necessarily prove lack of this ability.

The nature of the test substance may lead to an expectation concerning the direction of deviation of the preference ratio from 0.5. For example, if the test substance were sucrose, a preference ratio greater than 0.5 would be expected for above-threshold concentrations, whereas a preference ratio less than 0.5 would be expected for quinine. However, for a substance such as salt, preference may vary with concentration (Pfaffman, 1959).

In a series of experiments concerning PTC taste sensitivity of mice in the two-choice situation (Klein \& DeFries, 1970), Ss from each of five inbred strains avoided the PTC solution at relatively high concentrations. In a subsequent genetic analysis, taste sensitivity was thus measured as avoidance of the PTC solution. However, of the 430 Ss tested in this latter study, several were observed to have unusually high scores (preference ratio $>$.9). Such high preference ratios indicated almost perfect discrimination, but resulted in preference rather than avoidance. In order to maintain an interpretation of these data consistent with that applied to the results of the initial study, the rejection rule of Anscombe and Tukey (premium value $=.025$; Snedecor $\&$ Cochran, 1967) was applied. This procedure provides for deletion of a S's score when the deviation from its expected value suggests a gross error. Application of this procedure led to the rejection of seven Ss. The remaining data were subjected to several analyses that yielded evidence concerning the adequacy of a single-locus model. In all cases, the results were consistent with a hypothesis of single-locus determination of individual differences in taste sensitivity to PTC in mice, similar to that in man.

Although the use of the preference ratio resulted in a reasonable interpretation of the data described above, some difficulties with this measure were encountered. When the preference ratio is used, avoidance of the test solution is indicated by positive values less than 0.5 , understandably leading to some confusion. An index that more obviously differentiates avoidance and preference and that utilizes a scale from
-1.0 to +1.0 may be calculated as follows: Preference Index $=2$ (Preference Ratio -0.5 ). Thus, a preference index of 1.0 is indicative of complete preference, a score of 0.0 indicates no preference, and a score of -1.0 indicates complete avoidance, i.e., negative preference.

In addition, the employment of the preference ratio as an index of taste sensitivity in the above analysis required the assumption that only avoidance was indicative of ability to taste. This assumption led to the rejection of scores of seven Ss. A measure of taste sensitivity that is independent of the hedonic quality of the test solution and that permits the inclusion of all Ss is clearly preferable. Such an index is provided by taking the absolute value of the preference index defined above. The primary objective of the present communication is to demonstrate an empirical test of the validity of this "taste sensitivity index." The goodness of fit of the data described below to a single-locus model provides such a test.

Members of two inbred strains of mice, BALB/cIbg and C57BL/Ibg, and their derived $F_{1}$, backcross $\left(B_{1}\right.$ and $\left.B_{2}\right), F_{2}$ and $\mathrm{F}_{3}$ generations were presented tap water and PTC solution in a two-choice situation. A concentration of $4.5 \mathrm{mg}$ PTC per liter of tap water, empirically identified as producing maximal differences between the two parental inbred strains, was used. In order to control for possible position preferences, the position of the two liquids was reversed daily. Amounts of PTC solution and tap water consumed were recorded daily for a period of 10 days. The mean preference ratio for Days 9 and 10 (the most consistent within-strain measure) was obtained for each $S$ and then used to calculate the preference index. The resulting distribution of preference index scores for each of the seven groups is presented in Table 1. The number of $\mathrm{Ss}$ rejected, as described above, is indicated in parentheses.

As may be seen in Table 1, members of the BALB strain generally avoid the PTC solution, whereas members of the C57BL strain do not. The distribution of preference index scores in the $F_{1}$ generation indicates directional dominance for avoidance. In order to test for the adequacy of a single-locus model, the method of Collins and Fuller (1968) was applied to these data. Using this method, the expected number of individuals in each 
Table 1

Distribution of Preference Index Scores for Two Inbred Strains of Mice and Their Derived Generations

\begin{tabular}{|c|c|c|c|c|c|c|c|c|}
\hline $\begin{array}{l}\text { Preference } \\
\text { Index }\end{array}$ & BALB & C57BL & F1 & B1 & B2 & $\mathrm{F} 2$ & F3 & $\begin{array}{c}\text { Taste } \\
\text { Sensitivity } \\
\text { Index }\end{array}$ \\
\hline-1.00 & & & & & & & & 1.00 \\
\hline-.80 & 33 & 4 & 38 & 42 & 20 & 29 & 56 & .80 \\
\hline-.60 & 3 & 5 & 7 & 4 & 5 & 8 & 10 & .60 \\
\hline-.40 & & 3 & 5 & 5 & 9 & 3 & 6 & .40 \\
\hline-.20 & & 8 & 1 & 2 & 11 & 6 & 9 & .20 \\
\hline .00 & 1 & 8 & 6 & 6 & 8 & 11 & 10 & .00 \\
\hline .20 & 1 & 8 & 3 & 1 & 5 & 1 & 3 & .20 \\
\hline .40 & 1 & 3 & & 1 & 1 & 1 & 2 & .40 \\
\hline .60 & & & & & 1 & 2 & 1 & .60 \\
\hline $\begin{array}{l}.80^{*} \\
1.00\end{array}$ & (1) & & & (2) & $1(1)$ & (2) & (1) & $\begin{array}{r}.80 \\
1.00\end{array}$ \\
\hline
\end{tabular}

* Numbers in parentheses indicate individuals in the highest class interval deleted in the original analysis.

Table 2

Tests of Goodness of Fit of Preference Index Data and

Taste-Sensitivity Index Data to a Single Locus Model*

\begin{tabular}{|c|c|c|c|c|c|c|c|c|}
\hline \multirow[b]{3}{*}{ Group } & \multicolumn{4}{|c|}{ Partial Data Set } & \multicolumn{4}{|c|}{ Complete Data Set } \\
\hline & \multicolumn{2}{|c|}{$\begin{array}{c}\text { Preference } \\
\text { Index }\end{array}$} & \multicolumn{2}{|c|}{$\begin{array}{l}\text { Taste-Sensitivity } \\
\text { Index } \\
\end{array}$} & \multicolumn{2}{|c|}{$\begin{array}{c}\text { Preference } \\
\text { Index }\end{array}$} & \multicolumn{2}{|c|}{$\begin{array}{c}\text { Taste-Sensitivity } \\
\text { Index }\end{array}$} \\
\hline & $x^{2}$ & $\mathrm{p} \approx$ & $x^{2}$ & $\mathrm{p} \cong$ & $x^{2}$ & $\mathrm{p} \cong$ & $\chi^{2}$ & $\mathrm{p} \cong$ \\
\hline $\begin{array}{l}\text { B1 } \\
\text { B2 } \\
\text { F2 } \\
\text { F3 }\end{array}$ & $\begin{array}{l}1.42 \\
2.75 \\
2.66 \\
1.89\end{array}$ & $\begin{array}{l}.70 \\
.43 \\
.45 \\
.60\end{array}$ & $\begin{array}{l}1.74 \\
3.26 \\
3.14 \\
2.02\end{array}$ & $\begin{array}{l}.63 \\
.36 \\
.38 \\
.56\end{array}$ & $\begin{array}{l}2.38 \\
2.62 \\
3.45 \\
1.66\end{array}$ & $\begin{array}{l}.50 \\
.46 \\
.33 \\
.64\end{array}$ & $\begin{array}{l}1.40 \\
3.01 \\
2.37 \\
2.14\end{array}$ & $\begin{array}{l}.71 \\
.39 \\
.50 \\
.54\end{array}$ \\
\hline Total & 8.72 & .38 & 10.16 & .26 & 10.11 & .26 & 8.92 & .35 \\
\hline
\end{tabular}

* $d f$ for each group $=2$, df for total $=8$

class interval is determined for each of the segregating generations $\left(B_{1}, B_{2}, F_{2}\right.$, and $\left.F_{3}\right)$. These expected frequencies are obtained from data of the parental and $F_{1}$ generations by multiplying the observed frequency of each genotype by its expected proportion and then summing across genotypes. A chi-square test of goodness of fit is then applied to ascertain the adequacy of the model. Due to small expected frequencies, values between preference index category limits of -.80 and -.20 were pooled, as well as those above -.20. As may be seen in Table 2, chi-square tests of preference index data (partial data set) provided no evidence for a departure from expectation.
Due to the undesirability of deleting Ss, a reanalysis of the complete data set was undertaken using the taste-sensitivity index. When this index is applied, Ss previously deleted (preference index $>0.8$ ) may be included. In fact, in order to obtain an unbiased sample of taste-sensitivity data, the inclusion of these Ss is essential. The method of Collins and Fuller was again applied, first to the partial data set $(\mathrm{N}=423)$ and then to the complete data set $(N=430)$. For the sake of comparison, this method was also applied to the preference index data, complete data set. Resulting chi-square values for each segregating group and accompanying $p$ values are also presented in Table 2 .
As indicated in Table 2, the probability associated with the total chi-square value is less when the partial data set is described by the taste-sensitivity index. Thus, when only the partial data set is examined, the preference index provides a closer fit to a single-locus model. However, the partial data set was obtained by deleting Ss that clearly discriminated between the PTC solution and water but that preferred the PTC solution. Assuming that a single-locus model accounts for individual differences in taste sensitivity, rather than avoidance, the inclusion of these Ss should lead to a closer fit to the single-locus model when the taste sensitivity index is applied. As indicated in Table 2, application of this index to the complete data set increases the probability associated with the total chi-square value relative to the preference index, in agreement with the expectation.

Although the differences shown above are relatively small, the utility of the taste-sensitivity index that permits inclusion of all Ss is supported. In this case, a priori information concerning the single-locus model facilitated the demonstration of the validity of the taste-sensitivity index. This empirical test of the adequacy of alternative measures may prove useful in other contexts where some information concerning the mode of inheritance is available.

\section{REFERENCES}

COLLINS, R. L., \& FULLER, J. L. Audiogenic seizure prone (asp): A gene affecting behavior in linkage group VIII of the mouse. Science, $1968,162,1137-1139$

HARRIS, H., \& KALMUS, H. The measurement of taste sensitivity to phenylthiourea (P.T.C.). Annals of Eugenics, 1949, 15, 24-31.

KLEIN, T. W., \& DeFRIES, J. C. Similar polymorphism of taste sensitivity to PTC in mice and men. Nature, 1970, 25, 555-557.

PFAFFMANN, C. The sense of taste. In J. Field (Ed.), Handbook of physiology. Section 1: Neurophysiology. Vol. 1. Baltimore: Williams \& Wilkins, 1959.

SNEDECOR, G. W., \& COCHRAN, W. G. Statistical methods. (6th ed.) Ames: Iowa State University Press, 1967.

NOTE

1. Supported in part by NIH Grant GM-14547. 